\title{
FUNGSI TRADISI MEBANTEN TEBASAN \\ PADA HARI PANAMPAHAN GALUNGAN DI DESA BERINGKIT BELAYU KECAMATAN MARGA KABUPATEN TABANAN
}

\author{
Oleh \\ Ni Wayan Arini \\ Ni Nyoman Rai Triyantini
}

\begin{abstract}
ABSTRAK
Keberadaan aktifitas yajna khususnya di Bali, selain berperan sebagai suatu rutinitas spiritual keagamaan, juga berperan sebagai identitas keagamaan budaya dan tradisi. Suatu realita nyata yang terlihat di lapangan adalah pesatnya perkembangan tekhnologi era modern yang seolah melaju tanpa henti. Namun uniknya meski demikian pesat perkembangan tekhnologi, eksestensi budaya khususnya yajna di Bali tetap mampu bertahan bahkan bersinergi dengan perkembanganyang terjadi di masyarakat.

Hari raya Galungan sebagai hari pawedalan jagat, sehingga wajib memuja Ida Sang Hyang Widi atas terciptanya alam semesta beserta isinya, dan mengucapkan rasa terima kasih dengan ketulusan hati dan penuh kesucian atas kemurahan yang telah diberikan. Pada hari ini juga para dewa turun ke dunia termasuk juga para pitara yang merupakan leluhur kita. Dalam rangkaian hari raya Galungan mulai dirayakan pada hari Minggu Pahing Dungulan yang disebut Panyekeban. Biasanya umat Hindu mulai memproses buah-buahan yang masih mentah terutama pisang yang masih mentah agar matang pada saat hari Galungan tiba. Pada hari Senin Pon Dungulan dinamakan Panyajan pada waktu itu umat Hindu biasanya membuat berbagai macam kue atau jaja sebagai sesajen persembahan kepada para dewa pada hari raya Galungan. Kemudian pada hari Selasa Wage Dungulan dinamakan Panampahan. Barulah kemudian pada Rabu Kliwon Dungulan puncaknya hari suci Galungan, setelah Galungan dikenal hari manis Galungan.

Desa Beringkit Belayu merupakan salah satu wilayah yang memiliki tradisi yang cukup unik pada hari raya Galungan tepatnya pada hari Panampahan Galungan yaitu tradisi Mebanten Tebasan. Tradisi Mebanten Tebasan ini merupakan suatu aktivitas keagamaan yang bersifat kearifan lokal. Adapun fungsi tradisi Mebanten Tebasan yaitu Fungsi Meningkatkan Sradha dan Bhakti, Fungsi Sosial, Fungsi Pelestarian Budaya dan Fungsi Media Pendidikan.
\end{abstract}

Kata Kunci: Fungsi, Tradisi Mabanten Tebasan

\section{ABSTRACT}

The existence of yajna activities especially in Bali, besides acting as a religious spiritual routine, also acts as a cultural and traditional religious identity. A reality that is seen in the field is the rapid development of technology in the modern era that seems to go on without stopping. Despite of rapid technological development, cultural existence especially the Yajna in Bali is still able to survive and even synergize with developments in the community.

Galungan day is a day of pawedalan jagat, so we must worship Ida Sang Hyang Widi for the creation of the universe and its contents, and express our gratitude with sincerity and holiness for the generosity that has been given. On this day also the Gods descended to the world including the pitaras or our ancestors. In the series of Galungan festivals, it is celebrated on 
Sunday Pahing Dungulan called Panyekeban. Hindus usually begin to process fruits that are still raw, especially bananas that are still raw, so that they will be ripe on Galungan day. On Monday Pon Dungulan is named Panyajan. At that time Hindus usually made various kinds of cakes or jaja as offerings to the Gods at Galungan. Then, on Tuesday Wage Dungulan is called Panampahan. Then, on Wednesday Kliwon Dungulan is the peak of the Galungan day, after Galungan is known as Manis Galungan day.

Beringkit Belayu Village is one of the regions that have a fairly unique tradition at the Galungan holiday precisely on Panampahan Galungan day called Mebanten Tebasan tradition. The tradition is a local wisdom religious activity. The functions of the Mebanten Tebasan tradition are increasing Sradha and Bhakti, social functions, cultural preservation and the media education.

Keywords: Functions, Mabanten Tebasan Tradition.

\section{PENDAHULUAN}

Sastra-sastra suci yang dimiliki oleh umat Hindu telah banyak menekankan bahwa rutinitas yajna merupakan suatu kegiatan keagamaan yang dilaksanakan oleh umat Hindu (khususnya di Bali) dalam upaya turut serta memutar roda kehidupan di dunia beserta dengan segala isinya termasuk alam semesta untuk menuju kehidupan yang harmonis. Dalam realita aplikasinya, keagungan atau kesempurnaan suatu yajna dalam bentuk persembahan tidak dapat diukur dari kuantitas materi atau kemewahan dan kemegahan bentuk upacara itu sendiri, melainkan adalah dari nilai ketulus ikhlasan umat yang melaksanakan upacara tersebut. Dalam melaksanakan yajna masing-masing wilayah desa yang ada di Bali mempunyai aturan tersendiri yang disebut dengan Dresta atau Hukum Adat.

Keberadaan aktifitas yajna khususnya di Bali, selain berperan sebagai suatu rutinitas spiritual keagamaan, juga berperan sebagai identitas keagamaan budaya dan tradisi. Suatu realita nyata yang terlihat di lapangan adalah pesatnya perkembangan tekhnologi era modern yang seolah melaju tanpa henti. Namun uniknya meski demikian pesat perkembangan tekhnologi, eksestensi budaya khususnya yajna di Bali tetap mampu bertahan bahkan bersinergi dengan perkembangan yang terjadi di masyarakat. Meskipun tekhnologi memperoleh tempat yang sangat penting, namun eksistensi yajna di Bali tetap menduduki posisi sentral (utama), demi terciptanya keharmonisan.

Bertahannya budaya, adat dan tradisi di Bali selama ini karena Desa, Kala, Patra yang masih dipertahankan oleh masing-masing wilayah Desa di Bali. Desa merupakan tempat, Kala artinya waktu, dan Patra adalah keadaan. Menurut ketentuan waktu pelaksanaan yajna, umat Hindu mengenal dua jenis yajna yaitu 1) Nitya yajna yaitu yajna yang diselenggarakan/ dilaksanakan setiap hari. Contoh: Tri Sandhya, memberi suguhan yajna sesa (ngejot / saiban) dan 2) Naimitika yajna yaitu bentuk persembahan atau yajna yang dilaksanakan pada waktu khusus atau hari-hari tertentu berdasarkan tempat, waktu, dan keadaan (desa, kala, patra). Naimitika yajna terdiri dari a) Naimitika yajna yang berdasarkan pawukon, panca wara dan sapta wara yaitu yajna yang dipersembahkan berdasarkan perhitungan pertemuan panca wara dan sapta wara (pawukon) kehadapan Tuhan beserta manifestasinya, b) Naimitika yajna yang berdasarkan sasih yaitu persembahan yang dilaksanakan berdasarkan sasih atau bulan kehadapan Tuhan beserta manifestasinya dan c) Berdasarkan adanya peristiwa atau kejadian yang dipandang perlu

Fungsi Tradisi Mebanten Tebasan

Pada Hari Panampahan Galungan di Desa Beringkit Belayu Kecamatan Marga Kabupaten Tabanan 
untuk melaksanakan yajna (Sudirga, 200 : 86). Hari suci Galungan masuk dalam naimitika yajna yang berdasarkan pawukon. Hari suci ini tiba setiap enam bulan sekali (210 hari) yaitu pada hari Budha Kliwon Dungulan untuk merayakan kemenangan kebajikan (dharma) melawan kebatilan (adharma).

Suarka (2014:65-670) mengatakan hari raya Galungan sebagai hari pawedalan jagat, sehingga wajib memuja Ida Sang Hyang Widi atas terciptanya alam semesta beserta isinya, dan mengucapkan rasa terima kasih dengan ketulusan hati dan penuh kesucian atas kemurahan yang telah diberikan. Pada hari ini juga para dewa turun ke dunia termasuk juga para pitara yang merupakan leluhur kita. Dalam rangkaian hari raya Galungan mulai dirayakan pada hari Minggu Pahing Dungulan yang disebut Panyekeban. Biasanya umat Hindu mulai memproses buah-buahan yang masih mentah terutama pisang yang masih mentah agar matang pada saat hari Galungan tiba. Pada hari Senin Pon Dungulan dinamakan Panyajan pada waktu itu umat Hindu biasanya membuat berbagai macam kue atau jaja sebagai sesajen persembahan kepada para dewa pada hari raya Galungan. Kemudian pada hari Selasa Wage Dungulan dinamakan Panampahan. Barulah kemudian pada Rabu Kliwon Dungulan puncaknya hari suci Galungan, setelah Galungan dikenal hari manis Galungan.

Desa Beringkit Belayu merupakan salah satu wilayah yang memiliki tradisi yang cukup unik pada hari raya Galungan tepatnya pada hari Panampahan Galungan yaitu tradisi Mebanten Tebasan. Tradisi Mebanten Tebasan ini merupakan suatu aktivitas keagamaan yang bersifat kearifan lokal. Sepanjang pengetahuan peneliti, belum terdapat adanya suatu bentuk pendokumentasian, baik berupa hasil-hasil penelitian, maupun sumber-sumber yang memuat tentang fungsi, yang terkandung di dalamnya. Karena proses perkembangannya cukup lama, sehingga sering tidak diketahui lagi sumber serta alasan mengapa suatu perbuatan dilakukan pada waktu-waktu tertentu yang diyakini kebenarannya. Hal inilah yang menarik peneliti untuk meneliti fungsi pelaksanaan tradisi Mebanten Tebasan.

\section{Tradisi Mabanten Tebasan}

\subsection{Pengertian Tradisi Mabanten Tebasan}

Tradisi mebanten tebasan terdiri dari tiga kata, sehingga untuk memahami konsep banten tebasan maka perlu dipahami apa arti dari masing-masing kata tersebut. Yang pertama yaitu kata tradisi. Kata tradisi dalam bahasa Inggris disebut tradition berasal dari kata Latin tradition. Istilah dari tradition sendiri berasal dari kata tradire yang artinya menyerahkan (Bagus, 2002:1115). Tradisi juga disebut dengan Dresta. Menurut Wiratmaja (1975:17) bahwa dresta dinyatakan sebagai adat istiadat kegamaan atau kebiasaan yang harus dipelihara dan ditaati sebagai suatu peraturan selama hal itu tidak bertentangan dengan ajaran agama Hindu. Tradisi itu dipertahankan jika masih sesuai dan dapat diterapkan dalam masyarakat. Timbulnya tradisi disebabkan oleh falsafah Desa-KalaPatra, maka tradisi dapat disesuaikan dengan kebutuhan dan perkembangan jaman.

Banten merupakan bentuk upacara korban yang diwujudkan dalam bentuk sesajen yang dipersembahkan kepada Ida Sang Hyang Widhi Wasa. Pelaksanaan suatu upacara keagamaan dalam agama Hindu sangat berhubungan erat dengan sarana/ upakara banten. Banten adalah lambang dari pengorbanan suci yang harus dihaturkan dengan penuh keikhlasan dan kesucian hati. Banten memiliki arti yaitu suatu alat tanda bukti pernyataan terima kasih dan rasa syukur kehadapan Ida Sang Hyang Widhi Wasa dan banten merupakan bentuk daripada upakara-upakara yakni segala sesuatu yang berhubungan dengan perbuatan (Surayin, $2004: 5)$. 
Dalam Kamus Bali Indonesia (1993) dijelaskan bahwa tebasan berasal dari kata nebas artinya menebus, menebang, dan pembersihan. Tebasan atau tetebasan adalah nama sajen dalam upacara untuk menebus mala seseorang yang dilaksanakan setiap enam bulan yang dilaksanakan di Desa Beringkit Belayu pada hari Panampahan Galungan. Pada hakekatnya mempunyai tujuan yang sama yaitu sebagai penebusan. Banten tebasan dipakai dalam pelaksanaan upacara Dewa Yadnya, Pitra Yadnya, Rsi Yadnya, Manusa Yadnya, dan Bhuta Yadnya. Dalam beberapa hal khususnya menyangkut Manusa Yadnya, banten tebasan sering disebut dengan istilah sesayut. Apabila sesayut itu telah digunakan dalam upacara maka sesayut itu disebut dengan tebasan.

Selain itu tebasan memiliki banyak kegunaan, seperti sebagai suatu persembahan untuk memohon kepada Ida Sang Hyang Widhi Wasa agar dianugrahi kerahayuan, panjang umur, kesehatan, kebahagiaan, dan lain-lain. Sebagai suatu persembahan untuk memohon kesehatan, tebasan menunjukkan fungsinya sebagai "usada bebanten". Dikatakan demikian , karena hanya dengan sarana itu seseorang diharapkan dapat sembuh. Tebasan Panampahan ini terdiri dari kulit sesayut, raka-raka, sebuah penyeneng, nasi berwarna putih, sebuah takir berisi saur, sebuah takir berisi gerang, takir berisi timun, tuwung, dan kacang, sebuah takir berisi lawar, sebuah takir berisi daging babi goring, sebuah takir berisi daging kuah, sampian nagasari, sebuah takir berisi brengkes, dan sebuah takir berisi daging calon (PHDI, 2003:126).

Berdasarkan definisi tersebut, maka Tradisi Mebanten Tebasan merupakan upacara Manusa Yajna yang mempunyai arti suatu aktivitas keagamaan atau persembahan suci yang tulus ikhlas yang berguna sebagai pembersihan dan penebusan mala seseorang yang ditujukan kepada Ida Sang Hyang Widhi Wasa atau sebagai perwakilan yadnya yang dilaksanakan khususnya di Desa Beringkit Belayu pada hari Panampahan Galungan.

\subsection{Proses Tradisi Mabanten Tebasan}

Tradisi Mebanten Tebasan dilaksanakan tepatnya pada hari Panampahan Galungan yaitu pada Anggara Wage Dungulan. Namun rangkaian upacaranya sudah mulai pada hari panyekeban yaitu pada Redite Pahing Wuku Dungulan umat Hindu dipakai sebagai hari yang baik untuk memetik atau menyimpan buah-buahan seperti pisang pada tempat khusus (nyekeb) dari yang masih mentah hingga menjadi masak atau tasak. Bagi para wanita memulai majejahitan. Kemudian Hari Panyajahan yaitu pada Soma Pon Wuku Dungulan, yaitu masyarakat di Desa Beringkit Belayu menyiapkan semua perlengkapan dan sarana upacara seperti, menyiapkan bantenbanten, menghias merajan, dan membuat penjor. Dan pada Hari Panampahan Galungan masyarakat dari pagi sudah melaksanakan proses untuk persiapan tradisi Mebanten Tebasan pada sore harinya. Proses pembuatan banten tebasan yaitu mulai dari pembuatan sampian untuk upakara banten tebasan, metanding bunga, metanding jaja, dan sampai upakara untuk banten tebasan selesai.

Puncak tradisi Mebanten Tebasan yaitu pukul 18.00 Wita, pelaksanaannya dilakukan di Bale Bali. Sebelum anak laki-laki dalam keluarga tersebut melaksanakan rangkaian upacaranatab, pihak perempuanmelaksanakan prayascita di merajan dan pekarangan rumah. Setelah itu mempersembahkan banten canang soda di pelinggih Bhatara Hyang Guru untuk matur piuning bahwa anak lakilaki dalam keluarga itu akan melaksanakan natab banten tebasan yang disebut dengan banten tebasan panampahan dan nunas tirta di pelinggih Bhatara Hyang Guru. Selesai melaksanakan itu barulah prosesi natab tebasan dilaksanakan dengan urutan sebagai berikut : (1) Ngastawa upakara atau banten tebasan, (2) Pengambilan toya anyar yang di

Fungsi Tradisi Mebanten Tebasan

Pada Hari Panampahan Galungan di Desa Beringkit Belayu Kecamatan Marga Kabupaten Tabanan 
usapkan dikedua tangan menggunakan daun kayu sakti, (3) Tepung tawar yang berisi encakan daun kayu sakti dan tepung diambil dan diusapkan di kedua tangan, (4) Kembali diusapkan dengan toya anyar, (5) Nunas tirta dari pelinggih Bhatara Hyang Guru, (6) Mengambil benang tatebus (benang yang berwarna putih) diletakkan di penyeneng, di kepala yang melaksanakan natab tebasan, dan terakhir benang digelangkan di tangan yang natab tebasan dan nunas bija, dan (8) Pihak laki-laki natab banten tebasan

\section{Foto}

Pelaksanaan Pembersihan Menggunakan Toya Anyar dan Tepung Tawar Sebelum Natab Banten Tebasan Panampahan

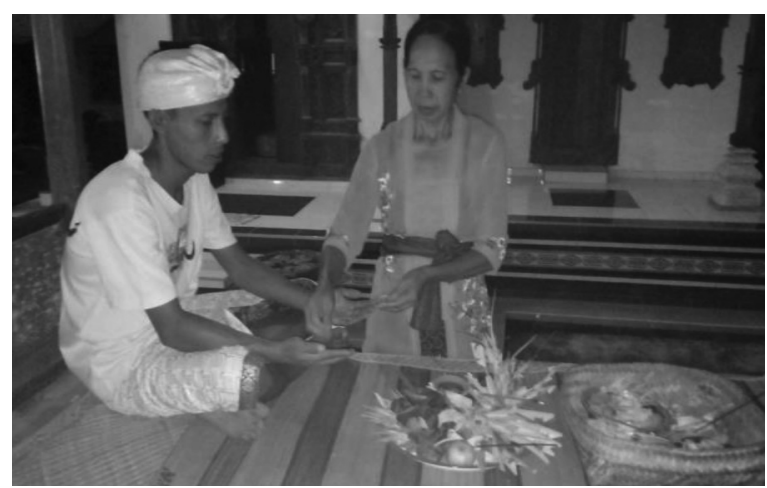

Sumber : Dokumen Peneliti, 2018

Foto di atas menggambarkan proses natab tebasan yaitu dimulai dengan mengambilkan toya anyar dan tepung tawar yang kemudian diusapkan di kedua telapak tangan. Langkah pertama yang dilakukan yaitu mengusapkan toya anyar di kedua tangan anak laki-laki yang natab tebasan kemudian diusapkan tepung tawar dan kembali diusapkan dengan toya anyar yang berfungsi sebagai keseimbangan hidup manusia.
Foto

Pelaksanaan Nunas Tirta dari Bhatara Hyang Guru

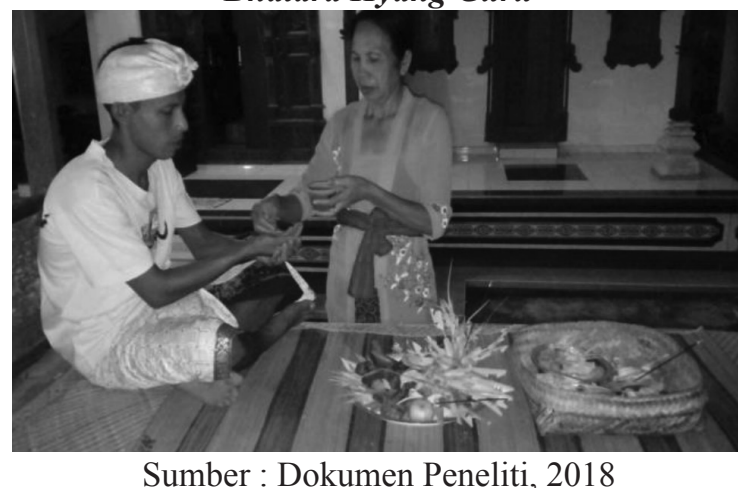

Foto di atas menggambarkan pihak laki-laki setelah selesai melaksanakan pembersihan dengan toya anyar dan tepung tawar dilanjutkan dengan nunas tirta dari Bhatara Hyang Guru. Nunas tirta Bhatara Hyang Guru di merajan dilakukan oleh pihak wanita sebelum melaksanakan natab banten tebasan.

Foto

Proses Natab Banten Tebasan Panampahan

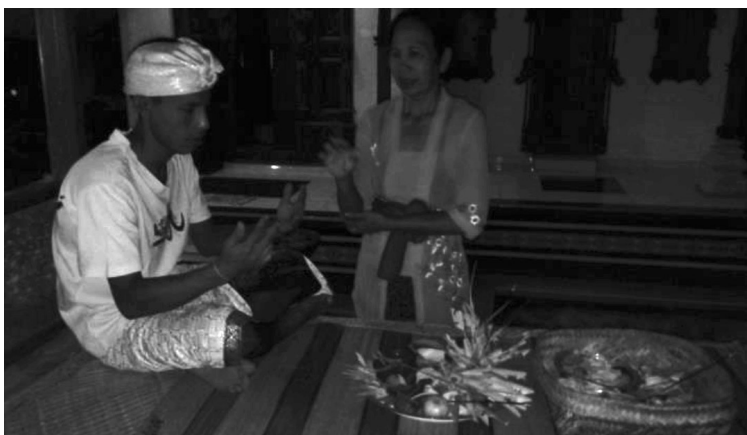

Sumber : Dokumen Peneliti, 2018

Rangkaian upacara tersebut dipimpin oleh orang yang lebih tua dan tradisi Mebanten Tebasan sebagai upacara manusa yajna yang dipersembahkan kepada Ida Bhatara Kawitan, Ida Bhatara di Pura Kahyangan Tiga, Sang Kala Kali Bebhuta, dan untuk menjaga keharmonisan dengan semua makhluk hidup. Dengan tujuan untuk menebus dan menetralisir mala seseorang selesai melaksanakan penyembelihan babi 
atau membunuh hewan lainnya untuk yajna pada pagi harinya.

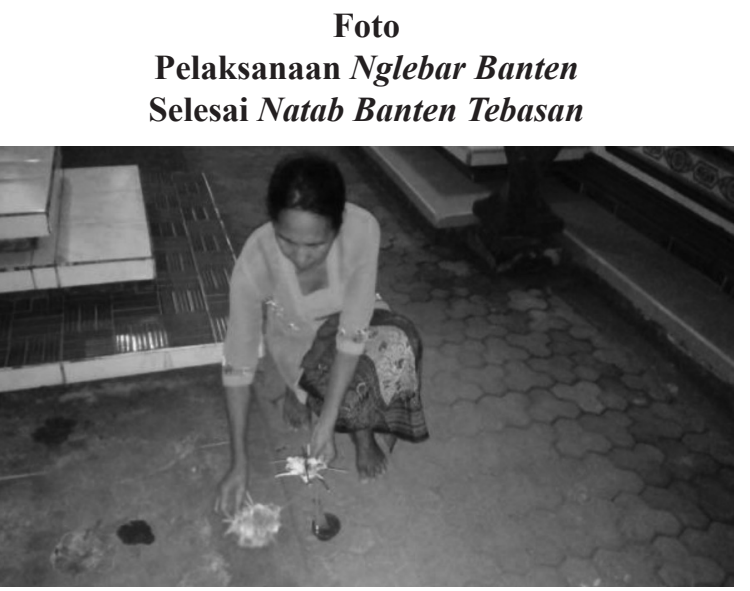

Sumber : Dokumen Peneliti, 2018

Adapun tahapan akhir dari tradisi Mebanten Tebasan adalah nglebar banten yaitu berupa banten canang soda yang dipakai saat natab tebasan, di atas canang itu berisi isi dari banten tebasan berupa nasi, lawar, daging goreng, daging kuwah, dan lainnya yang diambil sedikit-sedikit kemudian dihaturkan kepada Sang Kala Bhuta di nataran rumah untuk menjaga kerharmonisan antar sesama makhluk hidup dan alam sekitarnya serta mengatasi atau menebus bahaya yang akan datang.

Berdasarkan uraian di atas, maka proses tradisi Mebanten Tebasan pada hari Panampahan Galungan di Desa Beringkit Belayu, jika dikaitkan dengan teori yang dicetuskan oleh Talcot Persons maka masingmasing unsur dari suatu sistem kehidupan memiliki keteraturan yang saling berkaitan satu sama lain dari unsur tersebut baik dalam dasar pelaksaanaan tradisi Mebanten Tebasan, sarana upakara dalam tradisi Mebanten Tebasan, tempat dan waktu pelaksaanaan tradisi Mebanten Tebasan, pihak-pihak yang terlibat serta rangkaian pelaksanaan tradisi Mebanten Tebasan yang saling berkaitan dan tidak bisa terpisahkan sehingga masingmasing unsur bertujuan untuk menjaga keseimbangan dari suatu sistem kehidupan masyarakat tersebut khususnya masyarakat di Desa Beringkit Belayu dan dapat dikatakan relevan untuk menganalisis persoalan tentang proses tradisi Mebanten Tebasan tersebut.

\subsection{Fungsi Tradisi Mebanten Tebasan}

Adanya suatu tradisi tentunya memiliki fungsi dalam pelaksanaannya. Begitu pula dalam pelaksanaan tradisi Mebanten Tebasan pada hari Panampahan Galungan di Desa Beringkit Belayu terdapat beberapa fungsi didalam pelaksanaannya. Dengan menggunakan teori fungsional struktural yang dicetuskan oleh Talcot Persons, maka ditemukan beberapa fungsi yang terdapat dalam tradisi Mebanten Tebasan pada hari Panampahan Galungan di Desa Beringkit Belayu Kecamatan Marga Kabupaten Tabanan sebagai berikut.

\subsubsection{Fungsi Meningkatkan Sradha dan Bhakti}

Sradha berarti "yakin", "percaya", yang melandasi umat Hindu dalam meyakini keberadaan-Nya. Umat Hindu mendasari keyakinannya berjumlah lima, yang disebut dengan Panca Sradha. Panca Sradha meliputi : Brahman, keyakinan terhadap Tuhan, Atman, keyakinan terhadap atman, Karmaphala, keyakinan terhadap karmaphala (hukum sebab-akibat), Punarbhawa, keyakinan pada kelahiran kembali, dan Moksha, keyakinan akan bersatunya atman dengan Brahman.

Subagiasta (2007:15) menyatakan istilah bhakti artinya pengabdian sedangkan bagi pemuja Tuhan disebut dengan istilah bhakta. Pemujaan Tuhan dalam agama Hindu tiada lain adalah umat Hindu itu sendiri. Umat Hindulah sebagai bhakta. Dengan melakukan pemujaan kepada Ida Sang Hyang Widhi Wasa berarti umat Hindu telah melakukan pengabdian dirinya kepada Tuhan dengan segala manifestasinya. Wujud dan bentuk pengabdian kehadapan Ida Sang Hyang Widhi Wasa tersebut berupa material salah satunya

Fungsi Tradisi Mebanten Tebasan

Pada Hari Panampahan Galungan di Desa Beringkit Belayu Kecamatan Marga Kabupaten Tabanan 
berupa sarana atau banten. Sedangkan pengabdian secara spiritual adalah melalui kesucian pikiran dan rohani yang tulus untuk memuja Tuhan.

Berdasarkan penjelasan di atas maka fungsi Sradha Bhakti yang terdapat di dalam tradisi Mebanten Tebasan yaitu adanya keyakinan dan bhakti dalam proses pembuatan banten tebasan yang didasari dengan kesadaran dan penuh keikhlasan demi dapat mempersembahkan kehadapan Ida Sang Hyang Widhi Wasa dan segala manifestasinya, masyarakat Desa Beringkit Belayu melaksanakannya harus dengan bekerja sama sehingga terbentuk suatu sistem yang saling berhubungan satu sama lain.

\subsubsection{Fungsi Sosial}

Tradisi Mebanten Tebasan pada hari Panampahan Galungan secara sosial kemasyarakatan memiliki fungsi sebagai rasa kebersamaan dalam mewujudkan suatu tujuan mulia. Selain itu, dalam proses tradisi Mebanten Tebasan terjalin interaksi yang saling menghormati antar sesama masyarakat, keluarga dan kerabat dekat di Desa Beringkit Belayu. Dimulai dari proses nampah babi, mengolah babi menjadi sarana banten, dalam pembutan banten tebasan, dan natab banten tebasan.

Menurut Kamus Besar Bahasa Indonesia, istilah sosial secara etimologis mengarah pada hal yang berkenaan dengan masyarakat (Departemen Pendidikan dan Kebudayaan, 1990:885). Manusia dalam kehidupannya senantiasa berhubungan dengan masyarakat yang ada disekitarnya. Demikian pula dalam pelaksanaan upacara yajna yang secara fundamental (mendasar) akan membangkitkan jiwa kebersamaan dan jiwa kegotong royongan umat Hindu. Weda pun menegaskan bahwa hidup bermasyarakat merupakan hal yang penting di dunia ini, adapun ajaran tersebut dapat ditemui dalam Sloka Arthavaveda, 18.3. 75 yang menegaskan:
Etadā roha vaya unmrjānah svā

lha brhadu didayante,

Abhi prehi madhyato māpa

hāsthāh pitrnāam lokam

pratahamo yo

Terjemahan :

"wahai manusia, dengan menyucikan kehidupan ini tingkatkanlah kesejahteraan keluarga dan sahabatmu yang banyak memiliki keistimewaan, majulah engkau dari semua lapisan dan jangan meninggal dunia sebelum waktunya. Hiduplah dalam lingkungan keluarga, karena hidup bermasyarakat adalah hal yang penting di dunia ini" (Somvir, 2005 : 16).

Berdasarkan uraian di atas fungsi sosial yang terkandung dalam tradisi Mebanten Tebasan terlihat dari kebersamaan antar masyarakat, kerabat dekat, dan keluarga pada saat persiapan upakara yang didasari atas rasa kebersamaan dan rasa saling memiliki, sehingga dalam proses tradisi Mebanten Tebasan dapat terjalin sebuah interaksi sosial.

\subsubsection{Fungsi Pelestarian Budaya}

Kepekaan terhadap pengaruh budayabudaya asing yang bersifat negatif perlu mendapat perhatian khusus agar tidak terjadi pergeseran budaya bahkan menghilangkan kebudayaan leluhur yang ada dahulu. Fungsi pelestarian budaya dari tradisi Mebanten Tebasan pada hari Panampahan Galungan di Desa Beringkit Belayu tercermin dari masih tetapnya dilaksanakan upacara dengan menggunakan banten tebasan panampahan secara turun temurun oleh masyarakat Desa Beringkit Belayu.

Kebudayaan adalah salah satu keseluruhan yang kompleks yang terkandung didalamnya pengetahuan, kepercayaan, kesenian, moral, hukum, adat istiadat, dan kemampuan-kemampuan yang lain serta kebiasaan-kebiasaan yang didapat 
oleh manusia sebagai anggota dari suatu masyarakat. Untuk itu nilai-nilai budaya merupakan suatu bagian yang sangat penting untuk dilestarikan. Banyak sekali manfaat yang dapat diperoleh dari melestarikan nilainilai budaya, salah satunya yaitu budaya sebagai perekat bangsa (Harsojo, 1967:13).

Berdasarkan uraian di atas fungsi pelestarian budaya dalam tradisi Mebanten Tebasan yaitu diharapkan para generasi muda terutama generasi penerus dapat mengetahui dan bisa tetap melestarikan tradisi Mebanten Tebasan pada hari Panampahan Galungan di Desa Beringkit Belayu agar tidak hilang ataupun dilupakan seiring dengan perkembangan zaman.

\subsubsection{Fungsi Media Pendidikan}

Media pendidikan adalah suatu benda yang dapat diinderai, khususnya penglihatan dan pendengaran (alat peraga pengajaran) baik yang terdapat didalam maupun diluar kelas, yang digunakan sebagai alat bantu penghubung (medium komunikasi) dalam proses interaksi belajar mengajar untuk meningkatkan efektifitas hasil belajar siswa. Pada umumnnya media pendidikan dapat diklasifikasikan menjadi beberapa jenis adalah film strip, papan tulis, gambar-gambar, chart, grafik, poster dan peta rekaman pada tape rekorder. Sedangkan alat-alat yang dapat dilihat dan didengarkan misalnya film, televisi, dan benda-benda tiga demensi yang biasanya dipertunjukkan misalnya model, specemen dan lean boxes.

Tradisi Mebanten Tebasan memiliki fungsi sebagai media pendidikan yaitu sebagai media pendidikan terutama media pendidikan non formal yaitu pendidikan yang dilaksanakan dimasyarakat sebagai wadah untuk belajar praktek keagamaan karena para generasi muda dapat belajar secara langsung dari orang-orang yang lebih mengetahui tentang sarana upakara yang digunakan beserta cara membuatnya dan mereka dapat pengetahuan tentang fungsi media pendidikan dari masing-masing upakara tersebut. Pengetahuan yang mereka dapatkan nantinya diterapkan dalam kehidupan bermasyarakat dalam upaya melestarikan nilai-nilai yang ada di dalam tradisi Mebanten Tebasan pada hari Panampahan Galungan.

\section{Simpulan}

Berdasarkan hasil penelitian, fungsi tradisi Mebanten Tebasan pada hari Panampahan Galungan di Desa Beringkit Belayu, Kecamatan Marga, Kabupaten Tabanan dapat dikemukakan beberapa simpulan sebagai berikut : Fungsi tradisi Mebanten Tebasan pada hari Panampahan Galungan di Desa Beringkit Belayu antara lain Fungsi Meningkatkan Sradha dan Bhakti adalah adanya keyakinan dan bhakti dalam proses pembuatan banten tebasan yang didasari dengan kesadaran dan penuh keikhlasan demi dapat mempersembahkan kehadapan Ida Sang Hyang Widhi Wasa dan segala manifestasinya, Fungsi Sosial terlihat dari kebersamaan antar masyarakat, kerabat dekat, dan keluarga pada saat persiapan upakara yang didasari atas rasa kebersamaan dan rasa saling memiliki, sehingga dalam proses tradisi Mebanten Tebasan dapat terjalin sebuah interkasi iasl, Fungsi Pelestarian Budaya yaitu diharapkan para generasi muda terutama generasi penerus dapat mengetahui dan ias tetap melestarikan tradisi Mebanten Tebasan pada hari Panampahan Galungan di Desa Beringkit Belayu agar tidak hilang ataupun dilupakan seiring dengan perkembangan zaman, dan Fungsi Media Pendidikan yaitu sebagai media pendidikan terutama media pendidikan non formal sebagai wadah generasi muda belajar secara langsung mengetahui tentang sarana upakara yang digunakan beserta cara membuatnya dan mengetahui fungsi masing - masing upakara tersebut.

Fungsi Tradisi Mebanten Tebasan

Pada Hari Panampahan Galungan di Desa Beringkit Belayu Kecamatan Marga Kabupaten Tabanan 


\section{DAFTAR RUJUKAN}

Departemen Pendidikan Dan Kebudayaan. 1990. Kamus Besar Bahasa Indonesia. Jakarta : Balai Pustaka.

Harsojo. 1967. Pengantar Antropologi. Jakarta : Binatjipta.

PHDI. 2003. Panca Yadnya (Dewa Yadnya, Bhuta Yadnya, Resi Yadnnya, Pitra Yadnya dan Manusa Yadnya). Denpasar: Proyek Peningkatan Sarana dan Prasarana Pendidikan Beragama.

Somvir, Dr. 2005. 108 Mutiara Veda II. Denpasar : Panakom.

Suarka, I Nyoman. 2014. Sundarigama. Denpasar Timur : ESBE buku.

Subagiasta, I Ketut. 2007. Etika Pendidikan Agama Hindu. Denpasar : Paramita.

Sudirga, Ida Bagus, dkk. 2004. Agama Hindu. Bandung : Ganeca Exact.

Surayin, Ida Ayu Putu. 2004. Melangkah ke Arah Persiapan Upacara-Upacara Yadnya. Surabaya : Paramita.

Tim Penyusun, 1993. Kamus Bali Indonesia. Dinas Pengajaran Propinsi Daerah Tingkat I Bali.

Wiratmaja, Adi, I G K. 1975. Etika "Tata Susila Hindu Dharma". Denpasar : IHDN. 